EESTI NSV TEADUSTE AKADEEMIA TOIMETISED. XVII KOIDE

KEEMIA - GEOLOOGIA, 1968, Nr. 4

ИЗВЕСТИЯ АҚАДЕМИИ НАУК ЭСТОНСКОИ ССР. ТОМ ХVII

Химия * ГЕОлогия 1968, 수 4

И. КУДРЯВЦЕВ, К. ЛЭЭТС, М. ТАЛИ

\title{
ПОЛУЧЕНИЕ ЦИТРАЛЯ И ИОНОНОВ ИЗ СИНТЕТИЧЕСКИХ ГЕРАНИЛХЛОРИДОВ
}

В работе [1] описан синтез цитраля из терпеновых хлоридов $\mathrm{C}_{10} \mathrm{H}_{17} \mathrm{Cl}$, являющихся одним из компонентов реакции теломеризации изопрена с его гидрохлоридами. Селективное выделение геранилхлорида из смеси изомерных хлоридов осуществляетсq при этом количественно с помощью комплексообразования с уротропнном [2]. Для превращения соединения геранилхлорида с уротропином в цитраль использовалагь реакция Соммле $\left[{ }^{1,3}\right]$. Из синтезированного цитраля известными методами $\left[{ }^{4}\right]$ были. получены псевдононон и смесь $\alpha$ - и $\beta$-иононов. Однако изомерный состав полученного альдегида и иононов детально не был исследован.

Сведения о синтезе цитраля по реакции Соммле из геранилхлорида, получаемого тидрохлорированием мирцена $\left[{ }^{5}\right]$, в литературе не описаны.

В настоящєй работе указанные реакции были исследованы более подробно с делью выяснения качества и изомерного состава получаемых продуктов.

Изучалась кинетика образования соединения геранилхлорида, содержащегося во фракции хлоридов $\mathrm{C}_{10}$ теломера изопрена, в растворе дихлорэтана с уротропином в зависимости от температуры и продолжительности реакции. Для выяснения характера протекания побочных реакций была разработана аналитическая методика анализа состава піродуктов реакции. Установлено, что побочная реакция представляет собой отщепление хлористого водорода от изомерных терпеновых хлорндов фракции $\mathrm{C}_{10}$. Ее скорость по отношению к скорости образовани: геранилхлорида с уротропином в изученных условиях остается почти лостоянной и составляет около $20 \%$, как это видно из табл. 1.

Таблица 1

Характеристика процесса получення соединения геранилхлорида с уротропином

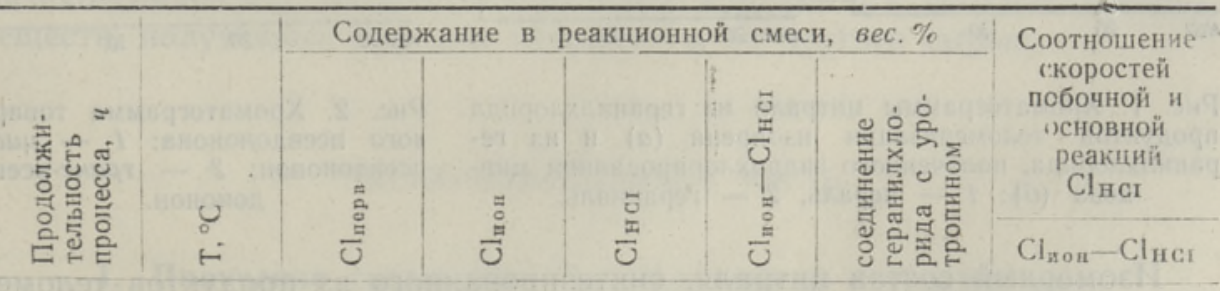

$\begin{array}{cccccccc}0,0 & 13 & 2,70 & - & - & - & - & \\ 1,0 & 20 & 2,10 & 0,149 & 0,019 & 0,13 & 0,15 & 0,15 \\ 2,5 & 20 & 1,86 & 0,450 & 0,070 & 0,38 & 3,34 & 0,19 \\ 6,25 & 20 & 1,65 & 0,830 & 0,126 & 0,704 & 6,20 & 0,18 \\ 16,0 & 20 & 0,92 & 1,18 & 0,240 & 0,940 & 8,27 & 0,25 \\ 28,0 & 20 & 0,39 & 1,76 & 0,28 & 1,480 & 13,0 & 0,19 \\ 32,0 & 20 & 0,07 & 2,04 & 0,33 & 1,710 & 15,0 & 0,19\end{array}$

3 ENSV TA Toimetised $\mathrm{K} * \mathrm{G} \cdot 468$ 
Целесообразно было для более полного и быстрого изв.течения целевого продукта провести реакцию с некоторым избытком уротропина ири умеренно повышенной температуре (около $35^{\circ} \mathrm{C}$ ). В избранных условиях выход соединения геранилхлорида с уғстропином составил $92 \%$ от теоретического.

Из выделенного соединения геранилхлорида с уротрогином синтетический цитраль был получен по методике [']. Выход его составил $65 \%$ по альдегиду. Среднее содержание альдегида в сыром продукте после отгонки растворителя достигало 85-90\%. Для выделения товарного цитраля были испытаны методы очистки полученного продукта вакуумной дистилляцией и гидродистилляцией непосредственно перед промывкой и после нее. Установлено, что товарный продукт отличного качества с наилучшим выходом можно получить вакуумной гидродистилляцией сырого продукта, предварительно промытого разбавленной минеральной кислотой. В выделенных товарных фракциях содержание цитраля составляет 96-100\%, причем все они обладают отличными парфюмерными качествами. Хроматограмма полученного чистого цитраля приведена на рис. $1 a$.

В аналогичных условиях цитраль был синтезирован из геранилхлорида, полученного гидрохлорированием мирцена. Выход его составил $56 \%$ от теоретического. Хроматограмма полученного цитраля изображена на рис. 16.

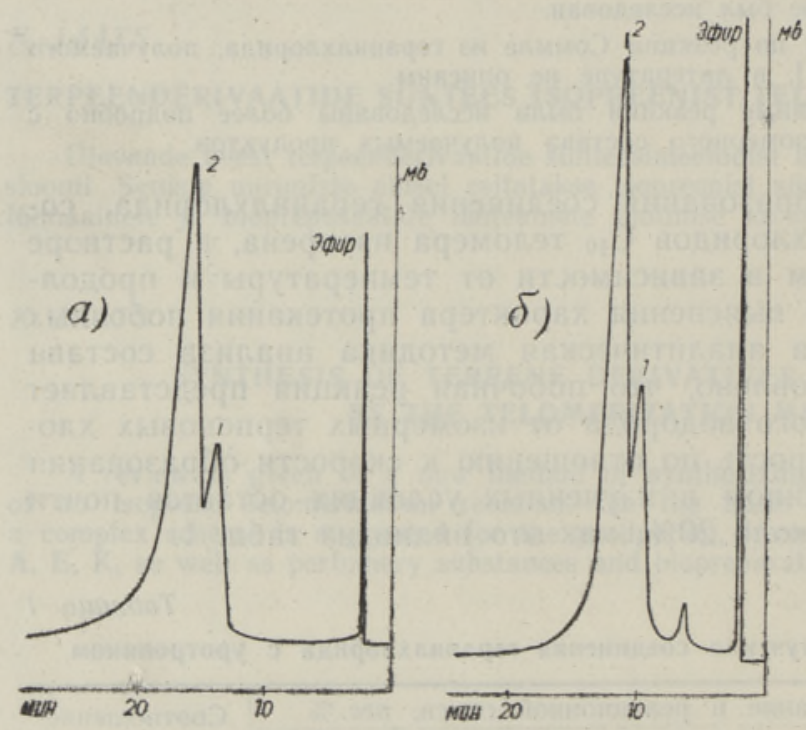

Рис. 1. Хроматограммы цитраля из геранилхлорида продуктов теломеризации изопрена $(a)$ и из reранилхлорида, полученного гидрохлорированием мирцена (б): 1 - нераль, 2 - гераниаль.

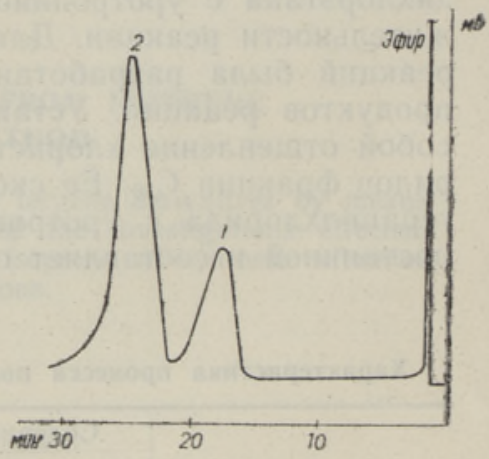

Рис. 2. Хроматограмма товарного псевдоионона: 1 - циспсевдононон; 2 - транс-псевдоионон.

Изомерный состав цитраля, синтезированного из продуктов теломеризации изопрена, незначительно отличается от состава цитраля, полученного из продуктов гидрохлорирования мирцена. В первом случае цитраль состоит из $80 \%$ гераниаля и $20 \%$ нераля, во втором - из $73 \%$ гераниаля и $27 \%$ нераля.

Получаемый по реакции Соммле цитраль не загрязнен побочными вешествами и не требует специальной очистки через бисульфитные 
соединения, обычно применяемой для выделения товарного продукта из природного сырья или из других синтетических продуктсв.

Для проверки методики синтеза и изомерного состава цитраля, полученного из продуктов теломеризации, были синтезирсваны псевдюионон и $\beta$-ионон методами, описанными в $\left[{ }^{4,6}\right]$. Установлено, что выход и качество псевдонононов, синтезированных из сырого цитраля, полученного по реакшии Соммле, и очищенного продукта практически не отличаются.

Как видно из хроматограммы (рис. 2), продукт содержкт по крайней мере два изомера. Чтобы доказать наличие в полученном продукте только цис-транс-изомерии, он был превращен в $\beta$-ионон по методике [6]. Синтезированный $\beta$-ионон, хроматограмма которого приведена на рис. 3 и 4 , по своим свойствам не отличается от $\beta$-ионона, полученного из природного цитраля по методике $\left.{ }^{6}\right]$, и содержит лишь небольшую

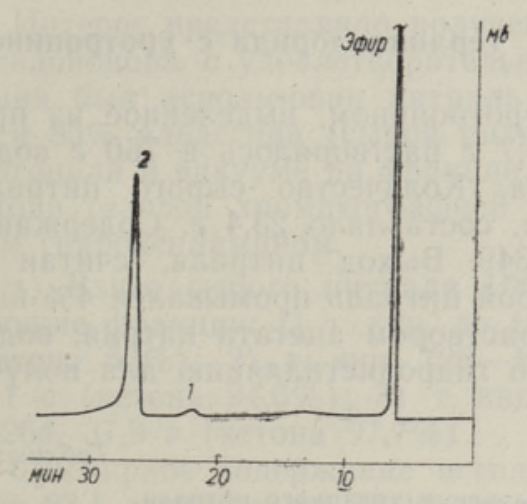

Рис. 3. Хроматограмма $\beta$-ионона (т. кип. $107-110^{\circ} ; 4$ м. рт. ст.): 1 - $a$-нонон; 2 $\beta$-ионон.

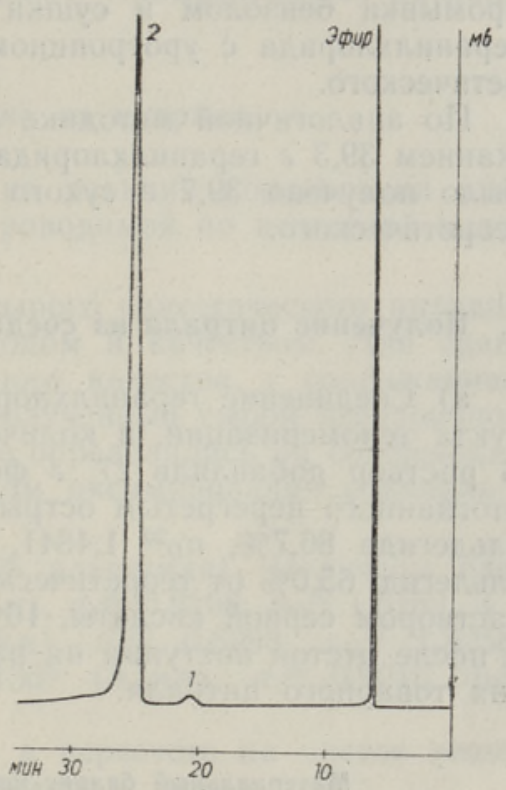

Рис. 4. Хроматограмма $\beta$ ионона (т. кип. $110-111^{\circ}, 4$ мм рт. ст.): 1 - $a$-ионон; 2 $\beta$-ионон.

примесь $\alpha$-ионона. Из этого можно сделать вывод, что установленные по хроматограммам изомеры синтетических цитралей и псевдонононов являются циис-транс-изомерами, чем объясняется некоторое различие в физико-химических свойствах указанных продуктов и соответствующнх веществ, полученных другими методами и из другого сырья.

\section{ЭКСПЕРИМЕНТАЛЬНАЯ ЧАСТЬ}

\section{1. Получение соединения геранилхлорида с уротропином}

Исходным сырьем служила фракция хлоридов $\mathrm{C}_{10}$ с содержанием $45 \%$ геранилхлорида. Реакция проводилась при $20^{\circ}$ и $10 \%$-ном избытке уротропина от стехиометрически необходимого количества. Растворитель был взят по весу в соотношении дихлорэтан : геранилхлорид $12: 1$. В соответствии с разработанной методикой контроля процесса в реак- 
ционной смеси через известные промежутки времени определялось содержание первичного хлора $\left(\mathrm{Cl}_{\text {перв}}\right)$, хлориона, нахсдящегося в виде $\mathrm{HCl}\left(\mathrm{Cl}_{\mathrm{HCl}}\right)$, и общее содержание хлориона $\left(\mathrm{Cl}_{\text {ион }}\right)$, характеризующих соответственно количество геранилхлорида, количество образовавшегося в результате вторичных реакций свободного хлористого водорода и суммарное количество хлорпроизводных в водной вытяжке анализируемой пробы. Количество соединения геранилхлорида с уротропином определялось по разности $\mathrm{Cl}_{\text {ион и }} \mathrm{Cl}_{\text {нсі }}$. Так же определялось содержание свободного уротропина. Результаты анализов приведены в табл. 1 .

Из 158,0 г фракции хлоридов $\mathrm{C}_{10}$ и 63,3 г уротропина при температуре $35^{\circ}$ и продолжительности процесса 16 ч было получено после промывки бензолом и сушки в вакууме 118,2 г чистого соединения геранилхлорида с уротропином, выход которого составил 92\% от теоретического.

По аналогичной методике из 100,0 г мирценгидрохлорида с содержанием 39,3 г геранилхлорида и 32 г уротропина при температуре $35^{\circ}$ было получено 39,7 г сухого продукта реакции с выходом $57,5 \%$ от теоретического.

\section{2. Получение цитраля из соединения геранилхлорида с уротропином}

а) Соединение геранилхлорида с уротропином, выделенное из продукта теломеризации, в количестве 63,7 г растворялось в 760 г воды. В раствор добавляли 27 г формалина. Количество сырого цитраля, отогнанного перегретым острым паром, составляло 23,4 2. Содержание альдегида $86,7 \%, n_{D}{ }^{20} 1,4841, d_{4}{ }^{20} 0,9349$. Выход цитраля, считая на альдегид, $65,0 \%$ от теоретического. Сырой цитраль промывался $4 \%$-ным раствором серной кислоты, $10 \%$-ным раствором ацетата натрия, водой и после отстоя поступал на вакуумную гидродистилляцию для получения товарного цитраля.

Таблица 2

Материальный баланс процесса получения товарного цитраля

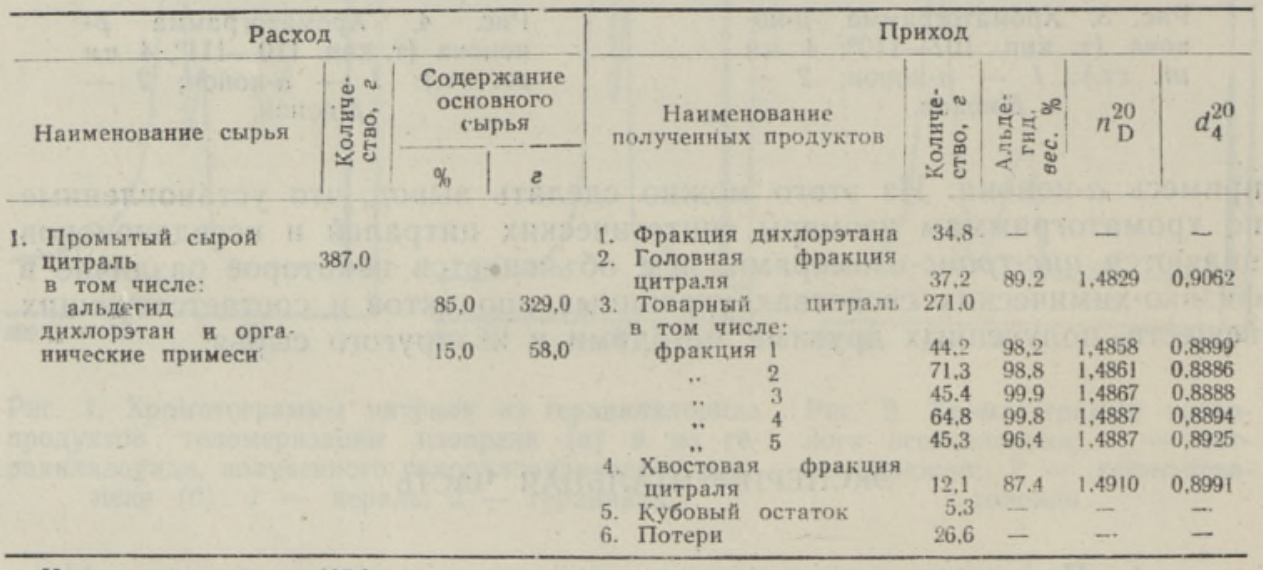

H тоro 387,0 H Toro

387,0

Как видно из материального баланса процесса (табл. 2), выход товарного цитраля высокого качества (96-100\%-ного содержания) составил $82,5 \%$ от альдегида сырого промытого цитраля.

Кроме того, повторная дистилляция соответственно объединенных нескольких головных, а также хвостовых фракций позволяет получит, 
дополнительное количество товарного цитраля (см. хроматсграмму на рис. 1).

б) Соединение геранилхлорида с уротропином, полученное из мирценгидрохлорида, в количестве 25,6 г растворялось в 270 г воды. В раствор добавляли 24 г формалина. Количество сырого цитраля, отогнанного перегретым острым паром, 8,0 г. Содержание альдегида $87,5 \%$. Выход цитраля, считая на альдегид, $56,3 \%$ от теоретического. После промывки разбавленной минеральной кислотой сырой продукт разгонялся в вакууме на фракции. Из 6 г сырого продукта было получено 5,05 г $(84,3 \%)$ товарного цитраля высокого качества с содержанием альдегида $99,3 \%, n_{D}{ }^{20} 1,4878, d_{4}{ }^{20} 0,8894$. Хроматограмма цитраля приведена на рис. 16.

\section{3. Получение псевдоионона из цитраля}

Получение псевдоионона базируется на реакции конденсации цитраля и ацетона в присутствии щелочи, проводимой по известной методике [ $\left.{ }^{4}\right]$.

Интерес представляло получение из сырого синтетического цитраля псевдоионона с удовлетворительным выходом и качеством. Для сравнения был использован цитраль различного качества, с содержанием 98 и 85\% альдегида (сырой цитраль). Полученный сырой псевдоионон разгоняли в вакууме на фракции, которые определялись на содержание кетона газовой хроматографией и методом оксимирования солянокисльм гидроксиламином.

а) Взято сырого цитраля 106 г (85\% альдегида). Получены следующие фракции: 1) т. кип. до $126^{\circ}(3 \mu м), d_{4}{ }^{20} 0,9196, n_{D}{ }^{20} 1,5162,3$ г (кетона $53 \%) ; 2)$ т. кип. $126-130^{\circ}(3 \mathrm{s \mu}), d_{4}{ }^{20} 0,8998, n_{D}{ }^{20} 1,5258$, 47,1 г (кетона 94,6\%); 3) т. кип. $130-135^{\circ}$ (3 мм), $d_{4}{ }^{20} 0,9010, n_{D}{ }^{20}$ $1,5264,37,9$ г (кетона $97,7 \%$ ).

Суммарное содержание псевдоионона в пересчете на чистое вещество 83,1 2, выход его $73,0 \%$ от теоретического.

б) Взято товарного цитраля 73,3 г (98\% альдегида). Получены фракции: 1) т. кип. до $126^{\circ}(3 м \mu), d_{4}{ }^{20} 0,9128, n_{D}{ }^{20} 1,5188,5,2$ г (кетона $80,4 \%)$; 2) т. кип. $126-129^{\circ}(3$ м. $), d_{4}{ }^{20} 0,9002, n_{D}{ }^{20} 1,5280,23,8$ г (кетона $98,4 \%)$; 3) т. кип. $129-135^{\circ}$ (3 мм), $d_{4}{ }^{20} 0,8992, n_{D}{ }^{20} 1,5290,41,6$ ᄅ (кетона 94,2\%).

Суммарное содержание псевдоионона в пересчете на чистое вещество 66,8 2, выход его $73,5 \%$ от теоретического.

Хроматограмму товарного псевдоионона см. на рис. 2.

\section{4. Получение $\beta$-ионона из псевдоионона}

Реакция проводилась по методике [6].

Из 50 г псевдоионона с содержанием 94\% кетона было получено 34 сырого $\beta$-ионона, который разгонялся в вакууме на следующие фракции: 1) т. кип. $104-107^{\circ}(4 \mathrm{\mu M}), d_{4}{ }^{20} 0,9380, n_{D}{ }^{20} 1,5131,1,9$ ᄅ (кетона $83 \%)$; 2) т. кип. $107-110^{\circ}$ (4 мм), $d_{4}{ }^{20} 0,9436, n_{D}{ }^{20} 1,5190,21,7$ 2 $($ кетона $94,1 \%)$; 3) т. кип. $110-111^{\circ}$ (4 мм), $d_{4}{ }^{20} 0,9451, n_{D}{ }^{20} 1,5202$, 8,8 г (кетона 95\%).

Содержание кетона во фракциях определяли методом оксимирования солянокислым гидроксиламином, а также газовой хроматографией. Хроматограммы $\beta$-ионона приведены на рис. 3 и 4. 
В данной работе анализ цитраля и иононов методом газовой хроматографии проводился на хроматографе «Хром-1». Длина колонки с внутренним диаметром 3 мм составляла 7 м. Наполнителем служил хромосорб $W$, пропитанный полиэфиром адипиновой кислоты с гликолем в количестве 4\%. Цитраль определялся при температуре $140^{\circ}$, иононы - при $160^{\circ}$.

\section{5. Методика анализов продуктов при получении соединения геранилхлорида с уротропином}

Отобранная при хорошем перемешивании из реакционной смеси средняя проба в количестве 2 г экстрагировалась 10-кратным количеством дважды дистиллированной воды и отстаивалась. Нижний слой, дихлорэтановый раствор изомерных хлоридов, высушивался над хлористым кальцием и затем над прокаленным поташом. В высушенном слое определялось содержание первичного аллильного хлора по методике [7]. Верхний, водный слой взвешивали. В нем определяли содержание хлориона $\left(\% \mathrm{Cl}_{\text {ион }}\right)$ по следующей методике. $\mathrm{K}$ навеске вещества $(5-6$ 2) добавляли 50 мл ацетона и 0,5 мл 0,5 н. раствора азотной кислоты, содержание хлориона определяли потенциометрическим титрованием 0,1 н. азотнокислым серебром.

Содержание в водном слое количества хлориона, находящегося в растворе в виде $\mathrm{HCl}$, и уротропина определялось совместно. К навеске Бодного слоя $(9-10$ 2) добавляли 20 м. ацетона и смесь титровали 0,5 н. раствором гидроокиси натрия в присутствии фенолфталеина до. бледно-розовой окраски. Затем добавляли бромфеноловый синий й смесь титровали обратно 0,5 н. раствором соляной кислоты до перехода синей окраски в желтовато-зеленую. По количеству щелочи вычисляли содержание хлориона, находящегося в растворе в виде соляной кислоты $\left(\% \mathrm{Cl}_{\mathrm{HCl}}\right)$, по количеству израсходованной кислоты - содержание уротропина в растворе.

Результаты анализа приведены в табл. 1.

\section{Выводы}

1. Изучен способ получения синтетического цитраля из геранилхлоридов - продуктов теломеризации изопрена и гидрохлорирования мирцена - с помощью реакции Соммле.

2. Установлено, что товарный продукт отличного качества с наилучшим выходом получается вакуумной гидродистилляцией сырого продукта реакции, предварительно промытого разбавленной минеральной кислотой.

3. Цитраль, выделенный из продуктов теломеризации изопрена, состоит из $20 \%$ цис-изомера и $80 \%$ транс-изомера; цитраль, образующийся из продуктов гидрохлорирования мирцена, состоит из $27 \%$ иисизомера и $73 \%$ транс-изомера.

4. Из сырого продукта реакции Соммле синтезирован конденсацией с ацетоном псевдоионон, который был превращен в $\beta$-ионон хсрошего качества. 
3. Ан жи ал С. Д., Органические реакции, сб. 8, 263, М., ИЛ, 1956.

4. И с агулянц В. И., Синтетические душистые вещества, Изд-во АН АрмССР, 1947, c. 391 .

5. Скв орцов а Н. И., Эрлих И. П., Тр. ВНИИСНДВ, вып. VII, 69 (1965).

6. Krishna H. I. V., I os hi B. N., J. Org. Chem., 22, 224 (1957).

7. Лээтс К. В., Пилявская А. И. и Коровкина М. И., ЖОХ, 27, 2969 (1957).
Ннститут химии
Академии наук Эстонской ССР
Поступила в редакцию
24/IV 1968

\section{KUDRJAVTSEV, K. LÄATS, M. TALI}

\section{TSITRAAL JA JONOONID SUNTEETILISTEST GERANUULKLORIIDIDEST}

Tsitraal sünteesiti Sommelet' reaktsiooni abil isopreeni telomerisatsioonil ja mürtseeni hüdrokloorimisel saadavatest geranüülkloriididest. Puhtad produktid saadi lahjendatud mineraalhappega eelnevalt pestud toorreaktsiooniprodukti hüdrodestillatsioonil vaakuumis. Isopreeni telomerisatsiooniproduktist saadav tsitraal sisaldas $20 \%$ tsiss- ja $80 \%$ transisomeeri; mürtseeni hüdrokloorimisproduktist saadi vastavalt $27 \%$ tsiss- ja $73 \%$ transisomeeri. Saadud toortsitraalist sünteesiti atsetooniga kondenseerides pseudojonoon ja $\beta$-jonoon.

\section{KUDRYAVTSEV, K. LÄATS, M. TALI}

\section{CITRAL AND IONONES FROM SYNTHETIC GERANYLCHLORIDE}

Citral was synthesized by Sommelet reaction from geranylchloride obtained as a product of isoprene telomerization or that of hydrochlorination of myrcene. The pure products were prepared by steam distillation from crude products preliminarily washed with diluted mineral acids.

Citral from isoprene telomerization product contained 20 per cent of cis and 80 per cent of trans-isomer, whereas in the case of the product from myrcene hydrochloride, these figures were 27 per cent and 73 per cent respectively. Pseudoionone and $\beta$-ionone were prepared from crude citral by condensation with acetone. 